\title{
Development of "Authentic Assessment" Instruments Basic Forehand and Backhand Groundstroke Techniques Based On "Actions Method" Learning Outcomes of Field Tennis Courses for Faculty of Sports Science of Yogyakarta State University Students
}

\author{
Ngatman Ngatman ${ }^{1, *}$ Guntur Guntur ${ }^{1,}$ Hari Yuliarto $^{1,}$ Sridadi Sridadi $^{1}$
}

\author{
${ }^{I}$ Faculty of Sport Science, Universitas Negeri Yogyakarta, Indonesia \\ ${ }^{*}$ Corresponding author.Email:ngatman@uny.ac.id
}

\begin{abstract}
To conduct an assessment of the basic forehand and backhand groundstroke skills of student learning outcomes in the field tennis sport course, an accurate/precise assessment instrument is needed. So far, the authentic assessment instrument to assess the learning outcomes of basic forehand and backhand groundstroke techniques that are in accordance with the characteristics of the tennis game for FIK UNY students is not yet available. The purpose of this study is to develop an authentic assessment instrument model for forehand and backhand groundstroke based on actions method learning outcomes for the tennis course students of Faculty of Sports Science of Yogyakarta State University. The research instrument uses a quantitative and qualitative approach (mixed method). The research subjects used were students of the PJKR FIK UNY Study Program who had taken Field Tennis Courses. Testing the validity of the content using Content Validity Ratio (CVR) analysis, testing the reliability of the model development using Consistency Alpha Cronbach statistical analysis, and to determine the reliability between raters using the Anova-General Multifacet Model. The results show that the authentic assessment instrument has very good content validity $(C V R)=0.50)$ and a high coefficient of reliability between raters $(r=0.80)$, successfully developed an authentic assessment instrument for basic forehand and backhand groundstroke techniques based on actions method consisting of: (1) Confidence and Mental Game (Psychology), (2) Prior to Stroke (Perception and Decision Stage), (3) Perform the Stroke and Stroke's Evaluation (Execution and Feedback Stage), and (4) Attitude and Behavior in Tennis Game. Thus, it can be concluded that the authentic assessment instrument for the basic forehand and backhand groundstroke based on the actions method can be used as an instrument for assessing the learning outcomes of the Court Tennis Court for FIK UNY students.
\end{abstract}

Keywords: Authentic assesment instrument, Forehand and backhand groundstroke, Actions method.

\section{INTRODUCTION}

Assessment is an integral part that cannot be separated from the learning process in university. To get the right assessment instrument model in assessing student learning outcomes, an assessment instrument is needed that can access all real/authentic performance of learning outcomes for the cognitive, affective, and psychomotor domains. Assessment that can be used to access all real student learning outcomes is called authentic assessment or performance-based assessment [1]. Authentic assessment is a form of task that requires students to show their performance in the real world in a meaningful way as the essence of the knowledge and skills that have been mastered. A similar opinion [2] which stated that authentic assessment is an assessment model that is applied in real-life situations, which requires students to use high-order thinking skills, such as problem solving and decision making in using skills possessed. The same opinion was also stated that performance-based assessment is an assessment in the form of a task that requires students to demonstrate performance in the real world in a meaningful way which is the application of the essence of knowledge and skills such as problem solving and decision making in using the skills they have [3]. He also stated that performance- 
based assessment is an assessment in the form of a task that requires students to demonstrate performance in the real world in a meaningful way which is the application of the essence of knowledge and skills.

Thus from the experts opinion it can be concluded that authentic assessment is a model for assessing student learning outcomes that is multidimensional or comprehensive and refers to the "real" world. From the various approaches in authentic assessment, it can provide the possibility that problem solving can be done in several alternatives. In other words, authentic assessment can monitor and measure students' abilities with various possible solutions to problems faced in the real world. On the basis of these considerations, in the learning process carried out by lecturers, it is hoped that standard assessment instruments will be available that can meet these requirements.

Field tennis is one of the subjects taught in all study programs at FIK UNY. At the end of every lecture on the practice of field tennis, the course lecturer always conducts an assessment to access the level of achievement of student learning outcomes. Field tennis is a sport that has complex motion characteristics, this is because tennis is a sport that falls into the category of open motor skills. Open motor skills have characteristics: the situation and conditions of the game that occur in the field are difficult to predict beforehand, the situation and environmental conditions that occur are always changing [4]. Tennis players never hit the same shot twice. Each stroke made by a player must consider four stages in the open skill process, which consist of: (1) perception (2) decision (3) execution, and (4) feedback. These four stages are the main characteristics of the actions method in today's modern tennis teaching [5].

The Actions Method is a tennis teaching method that emphasizes the framework for applying "what to do (tactical) by a tennis player", and is always closely related to "how to do (technical)" for a tennis player. According to [6], the action method is a tennis teaching method that provides a framework for integrating and developing each stage of the open skill process. The open skill process consists of: perception, decision, execution, and feedback. Actions method is a tennis teaching method that has 3 main forms (features). The three main features of the action method consist of: (1) in the learning process centered on the trained child (learned center), (2) combining technical and tactical frameworks, and (3) demanding that children train to always think critically every time they hit. Furthermore, [7] said that the action method gives students an understanding of the importance of developing reception skills and projection skills through an open skill process that is indispensable in the game of tennis.

At this time, FIK UNY has several problems faced by lecturers who teach tennis courses, including: (a) assessments conducted by lecturers on the learning outcomes of students' basic forehand and backhand groundstroke techniques are still using an expert sports skill test assessment from abroad several decades ago. The sport skill test made is only limited to measuring the level of mastery of basic techniques and has not actually measured student performance in accordance with the actual situation of playing tennis. The use of the assessment model through the sport skill test according to [8] is a predictor that is considered "invalid" in measuring students' abilities when playing actually, (b) FIK UNY does not yet have a standardized assessment instrument that can be used to assess learning outcomes for forehand basic techniques and backhand groundstroke for students (c) tennis course lecturers still have difficulty determining standard criteria in the assessment, both the process and the results of the basic forehand and backhand groundstroke techniques based on the action method, (d) based on the results of interviews with tennis lecturers from The PKO, IKORA, PJKR and PGSD Penjas FIK UNY study programs so far have used a subjective rating of $90 \%$ of the basic forehand and backhand groundstroke technique assessment instruments. The use of this subjective rating assessment is due to the fact that the lecturer in Field Tennis Course has not mastered and understood the performance-based assessment model (authentic assessment) forehand and backhand groundstroke basic techniques. Exploring the problems mentioned above, the researcher continued by conducting a needs analysis through a questionnaire instrument and interviews with students from the four study programs who had taken the tennis course. The search results through questionnaires and interviews show that the Study Programs (PKO, IKORA, PJKR and PGSD Penjas) at FIK UNY really need standardized assessment instruments that can be used to really assess the performance of students' learning outcomes forehand and backhand groundstroke.

Given the importance of the existence of an assessment model that can be used to access the learning outcomes of the basic technical skills of playing tennis for students authentically from the cognitive, affective, and psychomotor domains, the lecturer in tennis courses should: not only focus on one psychomotor assessment model (conventional assessment through sport skill test) which has been very entrenched among lecturers, is not only always a user of assessment instruments that have been made by experts from abroad several decades ago and is not necessarily in accordance with the level of ability and characteristics of FIK students. UNY. While this conventional assessment model is still maintained, there are concerns that the assessment carried out by lecturers is not sufficiently informed to keep up with the rapidly changing paradigm of the education system in university.

Based on the background of the problem and needs analysis as described above, this is what inspired the author to have the idea of conducting research as a 
solution to solve these problems. As an answer to these problems, the author creates a concept to develop an authentic assessment instrument for basic forehand and backhand groundstroke based on actions method learning outcomes of tennis courses for students of FIK UNY.

\section{METHODS}

The research procedure used in this development research adopts the development research model of [9] with the research steps as set out in the figure 1 .

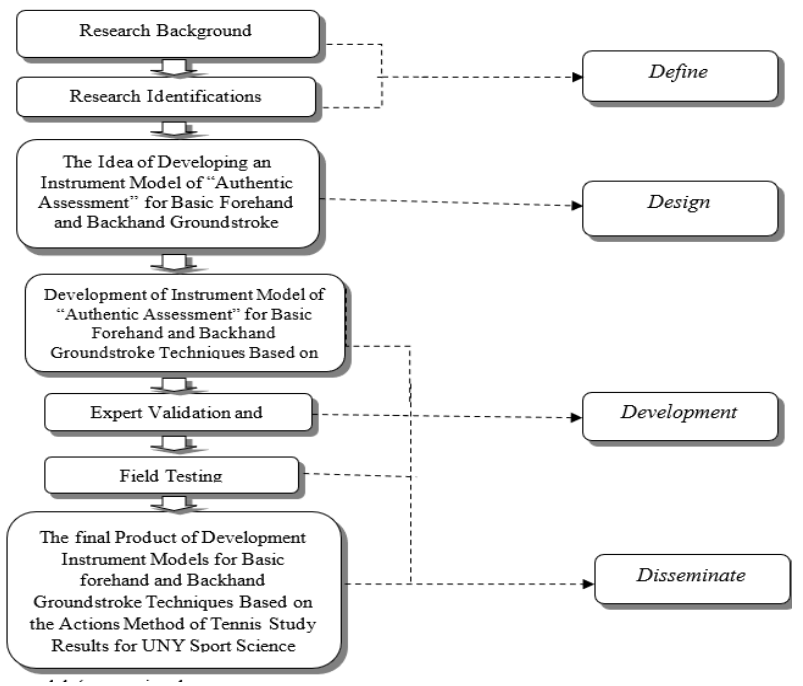

Figure 1 Research procedure flow with modification.

The subjects used in this development research are students from the PJKR, PKO, IKORA, and PGSD Penjas Study Programs, FIK, Yogyakarta State University who have taken Field Tennis Courses for the 2020/2021 Academic Year.

The assessment of the learning outcomes of basic forehand and backhand groundstroke techniques in playing tennis is carried out using a competition match with the "Pro Set Tie Break" system which is assessed by 5 tennis experts through subjective rating expert judgment.

In assessing during the competition, the raters use an assessment instrument sheet containing factors and indicators from the authentic assessment rubric, basic techniques for forehand and backhand groundstroke tennis based on the actions method that has been developed by the researcher. The authentic assessment instrument that has been compiled has gone through stages of validation by experts in the field of tennis and material experts in the field of measuring and evaluating PJOK.

The data analysis to be carried out in this development research is as follows:

1. To test content validity, the Development of the "Authentic Assessment" Instrument Model was analyzed using the CVR (Content Validity Ratio) formula [10]:

$\mathrm{CVR}=\left[2 \frac{M p}{M}\right]-1$

Information:

$\mathrm{Mp}=\sum$ Expert who gives good marks (Rating 3-4)

$M=$ Number of experts

$1=$ Results by Experts

2. Determination of the reliability coefficient using the Genova program package based on the Generalizability theory developed by Cric and L. Brennan.

3. To determine the reliability between raters (intertester reliability) using the Anova-General Multifacet Model.

\section{RESULTS AND DISCUSSION}

\subsection{Results}

Based on the results of the needs analysis through preliminary studies, theoretical studies, and relevant research results, an initial draft of an authentic assessment instrument is prepared. The draft of the authentic assessment instrument consists of: (1) the stages of the technical open skill process basic forehand and backhand groundstroke based on the actions method, (2) compiling a grid of basic techniques forehand and backhand groundstroke based on the actions method, (3) observation sheets along with guidelines for assessing basic forehand and backhand groundstroke techniques, (4) compiling task sheets and test implementation instructions, observation sheets, and scoring systems.

Authenthic assessment instrument draft basic forehand and backhand techniques groundstroke based on the actions method that has been compiled and then tested for validation to five experts who have been appointed to get suggestions and input.

Table 1. The results of the assessment of the experts

\begin{tabular}{|c|c|c|}
\hline Experts & Mark & Information \\
\hline 1 & 4 & Good \\
\hline 2 & 3 & Good \\
\hline 3 & 4 & Good \\
\hline 4 & 3 & Good \\
\hline 5 & 4 & Good \\
\hline
\end{tabular}

From the results of the assessment that has been carried out by experts, then a content validity analysis is carried out using the Content Validity Ratio (CVR) formula from Lawshe's:

$\mathrm{CVR}=\left\{\left(\mathrm{Ne}-\frac{N}{2}\right) / \frac{N}{2}\right\}$ 
Information:

$$
\begin{aligned}
& C V R=\text { Conten Validity Ratio } \\
& \mathrm{Ne}=\text { Number of expert judgement/ } \\
& \mathrm{N} \quad=\text { Total number of panelists }
\end{aligned}
$$

The results of the assessment of the five expert validators turned out to give good scores on the authentic assessment instrument draft basic forehand and backhand techniques groundstroke based on the developed action method. The results of content validity using the CVR formula obtained results of 1.00 . Thus it can be said that the authentic assessment instrument model can be continued to the next stage after being revised according to suggestions and input from experts.

After going through the stages of development along with the steps of in-depth development research, finally a grid of assessment rubrics has been successfully compiled. The rubric of the authentic assessment instrument for forehand and backhand basic techniques produced consists of: (1) authentic assessment observation sheet for forehand and backhand groundstroke based on the actions method that is used to assess students when playing tennis, (2) an assignment sheet for playing tennis during $1 / 2$ match, (3) instructions and guidelines for filling out authentic assessment observation sheets, and (4) scoring sheets for the final assessment of learning outcomes for forehand and backhand groundstroke based on actions method.

\subsubsection{Observation Sheet of Authentic Assessment Instrument Model for Forehand and Backhand Groundstroke Based on Actions Method}

Table 2. Factors and indicators of authentic assessment

\begin{tabular}{|c|c|}
\hline Factor & Indicator \\
\hline $\begin{array}{l}\text { Confidence } \\
\text { and Mental } \\
\text { Game } \\
\text { (Psychology) }\end{array}$ & $\begin{array}{l}\text { - Have high confidence when going to do } \\
\text { forehand and backhand groundstrokes. } \\
\text { - Have the courage and don't hesitate in making } \\
\text { decisions every time you make forehand and } \\
\text { backhand groundstrokes (confident and don't } \\
\text { hesitate). } \\
\text { - Have mental toughness at critical points. } \\
\text { - The playing strategy that is applied is right at } \\
\text { the time of forehand and backhand } \\
\text { groundstroke. }\end{array}$ \\
\hline $\begin{array}{l}\text { Prior to } \\
\text { Stroke } \\
\text { (Perception } \\
\text { and Decision } \\
\text { Stage) }\end{array}$ & $\begin{array}{l}\text { - Ability to analyze game situations. } \\
\text { - Ability to adjust to the arrival of the ball. } \\
\text { - Positioning ability before hitting the ball. } \\
\text { - The accuracy of decision making before } \\
\text { making forehand and backhand groundstroke } \\
\text { volleys. } \\
\text { - Ability } 5 \text { ball control (read the trajectory of the } \\
\text { ball, anticipate the ball's direction, speed, } \\
\text { spin, altitude, distance, and depth of the ball). } \\
\text { - Retrieval ability attitude ready position, } \\
\text { balance, backswing, point of contact, and } \\
\text { follow throughout. }\end{array}$ \\
\hline $\begin{array}{l}\text { Perform the } \\
\text { Stroke and } \\
\text { Stroke's } \\
\text { Evaluation }\end{array}$ & $\begin{array}{l}\text { Decisions made when hitting the forehand } \\
\text { and backhand groundstrokes are made right, } \\
\text { effective, and efficient. }\end{array}$ \\
\hline
\end{tabular}
forehand and backhand groundstroke basic techniques

\begin{tabular}{|c|c|}
\hline $\begin{array}{l}\text { (Execution } \\
\text { and } \\
\text { Feedback } \\
\text { Stage) }\end{array}$ & $\begin{array}{l}\text { - Decisions made in making forehand and } \\
\text { backhand groundstrokes are effective in } \\
\text { making it difficult for the opponent to return } \\
\text { the ball. } \\
\text { - The decisions that have been made are } \\
\text { effective to earn points. } \\
\text { - Knowing the success and failure of every } \\
\text { forehand and backhand groundstroke that is } \\
\text { done consciously. }\end{array}$ \\
\hline \begin{tabular}{|l|} 
Attitude and \\
Behavior in \\
Tennis Game
\end{tabular} & $\begin{array}{l}\text { - After hitting the forehand and backhand } \\
\text { groundstroke, always return to the basic } \\
\text { position before hitting. } \\
\text { - While playing, he still shows a high fighting } \\
\text { spirit. } \\
\text { - Shows a disappointed gesture if an unforce } \\
\text { error occurs when hitting the forehand and } \\
\text { backhand groundstrokes. } \\
\text { - Shows the character to always be fair } \\
\text { play/sportsman when playing. } \\
\text { - Show respect for opponents. }\end{array}$ \\
\hline
\end{tabular}
based on actions method

\subsubsection{Assignment}

Students who are used as research subjects are given the task of conducting a tennis match with a competition system. The match system used is tie break pro set by looking for a score of 10 as the winner. At the time of playing the competition, the level of efficiency and effectiveness of the basic forehand and backhand groundstroke techniques was assessed based on the stages of the open skill process from the actions method used by students when playing tennis.

\subsubsection{Instructions and Guidelines for Completing the Basic Forehand and Backhand Groundstroke Techniques Observation Sheet Based on Actions Method}

Table 3. Instructions for Filling in and Observation

\begin{tabular}{|c|c|}
\hline Score & Description \\
\hline $\begin{array}{c}\text { "+" } \\
\text { (plus) } \\
\text { and } \\
\text { score } 3\end{array}$ & $\begin{array}{l}\text { If self-confidence, courage, no hesitation, mental } \\
\text { toughness, the right strategy is applied, high } \\
\text { motivation in hitting forehand and backhand } \\
\text { groundstrokes during playing tennis always } \\
\text { appears, between } 90-100 \% \text {. }\end{array}$ \\
\hline $\begin{array}{c}\text { "v" } \\
\text { (tick) } \\
\text { and } \\
\text { score } 2\end{array}$ & $\begin{array}{l}\text { If self-confidence, courage, no hesitation, mental } \\
\text { toughness, the right strategy is applied, high } \\
\text { motivation in hitting forehand and backhand } \\
\text { groundstrokes during play appears quite a lot, } \\
\text { between } 66 \%-89 \% \text {. }\end{array}$ \\
\hline $\begin{array}{c}\text { " - " } \\
\text { (minus) } \\
\text { and } \\
\text { score } 1\end{array}$ & $\begin{array}{l}\text { If self-confidence, courage, no hesitation, mental } \\
\text { toughness, the right strategy is applied, high } \\
\text { motivation in hitting forehand and backhand } \\
\text { groundstrokes during play appears a little, } \\
\text { between } 0-65 \% \text {. }\end{array}$ \\
\hline
\end{tabular}
Sheet for Confidence and Mental Game (Psychology Aspects)

Table 4. Instructions for Filling Out and Factor Observation Sheets Prior to Stroke (Stage: Perception and Decision)

\begin{tabular}{|c|l|}
\hline Score & \multicolumn{2}{|c|}{ Description } \\
\hline " + & If the analysis of the game situation, ball \\
(plus) & adjustment, placing the right hitting position, \\
and & decision-making ability, 5 ball control ability, and \\
score 3 & taking the position of the forehand and backhand \\
\hline
\end{tabular}




\begin{tabular}{|c|l|}
\hline & $\begin{array}{l}\text { groundstroke strokes always appear and are } \\
\text { carried out efficiently between } 90-100 \% .\end{array}$ \\
\hline "v" & $\begin{array}{l}\text { If the analysis of the game situation, ball } \\
\text { (tick) } \\
\text { and } \\
\text { adustment, placing the right hitting position, } \\
\text { score 2 } \\
\text { decision-making ability, 5 ball control ability, and } \\
\text { positioning forehand and backhand } \\
\text { groundstrokes appear quite a lot and are carried } \\
\text { out efficiently between } 66 \%-89 \%\end{array}$ \\
\hline "-" & $\begin{array}{l}\text { If the analysis of the game situation, ball } \\
\text { (minus) } \\
\text { adjustment, correct hitting position placement, } \\
\text { and } \\
\text { score 1 } 1 \\
\text { positioning for forehand and backhand } \\
\text { groundstrokes appear slightly and performed } \\
\text { efficiently between 0 - 65\%. }\end{array}$ \\
\hline
\end{tabular}

Table 5. Instructions for Filling in and Observation Sheets for Attitude and Behavior in Tennis Game

\begin{tabular}{|c|c|}
\hline Score & Description \\
\hline $\begin{array}{c}\text { " }+" \\
\text { (plus) } \\
\text { and } \\
\text { score } 3\end{array}$ & $\begin{array}{l}\text { If you return to the starting position (center mark) } \\
\text { before hitting the forehand and backhand } \\
\text { groundstrokes, showing consistent enthusiasm } \\
\text { when playing, showing good body gestures } \\
\text { during play, showing character and being fair } \\
\text { play when playing, and showing respect when } \\
\text { playing, it always appears between } 90 \%-100 \% \text {. }\end{array}$ \\
\hline $\begin{array}{c}\text { "v" } \\
\text { (tick) } \\
\text { and } \\
\text { score } 2\end{array}$ & $\begin{array}{l}\text { If you return to the starting position (center mark) } \\
\text { before hitting the forehand and backhand } \\
\text { groundstrokes, showing consistent enthusiasm } \\
\text { when playing, showing good body gestures } \\
\text { during play, showing character and being fair } \\
\text { play when playing, and showing respect when } \\
\text { playing, it appears quite a lot between } 66 \% \text { - } \\
89 \% \text {. }\end{array}$ \\
\hline $\begin{array}{c}\text { " - " } \\
\text { (minus) } \\
\text { and } \\
\text { score } 1\end{array}$ & $\begin{array}{l}\text { If returning to the initial position (center mark) } \\
\text { before hitting the forehand and backhand } \\
\text { groundstrokes, showing consistent enthusiasm } \\
\text { when playing, showing good body posture during } \\
\text { playing, showing character and being fair play } \\
\text { when playing, and showing respect when } \\
\text { playing, a little appears between } 0-65 \% \text {. }\end{array}$ \\
\hline
\end{tabular}

Besides getting observation sheets to assess student performance and guidelines for filling out authentic assessment basic forehand and backhand groundstroke techniques based on the actions method, a scoring sheet has also been developed to assess the final performance of learning to play tennis for students. For the purposes of the final assessment, the researcher used the assessment criteria as shown in table 6 below.

Table 6. Criteria for final performance assessment of authentic assessment instruments for forehand and backhand groundstroke based on actions method

\begin{tabular}{|c|c|}
\hline Average Score Interval & Category \\
\hline $2,25<$ score $\leq 3.00$ & Good \\
\hline $1,50<$ score $\leq 2,25$ & Moderate \\
\hline $1,00<$ score $\leq 1,50$ & Less \\
\hline
\end{tabular}

\subsubsection{Content Validation Results}

The result data from five tennis expert assessors on the scoring rubric grid by choosing 3 alternative answers consisting of: essential/important, useful but not essential, and useless can be seen in table 7 .
Table 7. Data on the results of the tennis expert's assessment of the factors of the Forehand and Backhand Groundstroke Basic Techniques based on the Actions Method

\begin{tabular}{|c|c|c|c|c|}
\hline \multirow{3}{*}{ Examiner } & \multicolumn{4}{|c|}{ Factor Assessment } \\
\hline & $\begin{array}{c}\text { Confidance } \\
\text { and Mental } \\
\text { Game } \\
\text { (Psychology) }\end{array}$ & $\begin{array}{c}\text { Prior to } \\
\text { Stroke } \\
\text { (Perception } \\
\text { and } \\
\text { Decision } \\
\text { Stage) }\end{array}$ & \begin{tabular}{|c|} 
Perform the \\
Stroke and \\
Stroke's \\
Evaluation \\
(Execution and \\
Feedback \\
Stage) \\
\end{tabular} & $\begin{array}{c}\text { Attitude } \\
\text { and } \\
\text { Behavior } \\
\text { in Tennis } \\
\text { Game }\end{array}$ \\
\hline & $(1)$ & $(2)$ & $(3)$ & (4) \\
\hline WNG & essential & essential & essential & essential \\
\hline $\mathrm{AAL}$ & essential & essential & essential & essential \\
\hline RNF & essential & essential & essential & essential \\
\hline PTK & essential & essential & essential & $\begin{array}{c}\text { useful but } \\
\text { not } \\
\text { essential }\end{array}$ \\
\hline YDT & $\begin{array}{c}\text { useful but not } \\
\text { essential }\end{array}$ & essential & essential & essential \\
\hline
\end{tabular}

Based on the recapitulation of the expert assessment results in table 7 above, it can be concluded that factor 1 (self-confidence and mental play/psychology) four assessors stated essence and 1 rater stated useful but not essence. Factor 2 (before hitting, stage: perception and decision from the actions method) five expert judges stated the essence. Factor 3 (when making a shot and evaluating the shot, stage: execution and feedback from the actions method) five assessors stated the essence. For factor 4 (attitude and behavior in playing tennis) 4 expert raters stated essence, while 1 rater stated useful but not essential.

From this data, it can then be analyzed using the Content Validity Ratio (CVR) with the results presented in table 8 .

Table 8. The results of calculating the CVR content validity of authentic assessment instruments forehand and backhand groundstroke basic techniques based on actions method

\begin{tabular}{|l|c|}
\hline $\begin{array}{l}\text { Factors of Authentic Assessment } \\
\text { Instruments Basic Forehand and } \\
\text { Backhand Groundstroke Techniques } \\
\text { Based on Actions Method }\end{array}$ & $\begin{array}{c}\text { Content } \\
\text { Validity } \\
\text { Coefficient } \\
\text { (CVR) }\end{array}$ \\
\hline $\begin{array}{l}\text { Confidence and Mental Game } \\
\text { (Psychology) }\end{array}$ & 0,60 \\
\hline $\begin{array}{l}\text { Prior to Stroke (Perception and Decision } \\
\text { Stage) }\end{array}$ & 1.00 \\
\hline $\begin{array}{l}\text { Perform the Stroke and Stroke's } \\
\text { Evaluation (Execution and Feedback } \\
\text { Stage) }\end{array}$ & 1,00 \\
\hline Attitude and Behavior in Tennis Game & 0,60 \\
\hline
\end{tabular}

All factors and indicators have a content validity coefficient of $>0.50$. Thus, the factors and indicators of the instrument can be used as an authentic assessment instrument to assess the basic forehand and backhand groundstroke techniques based on the actions method. This is in accordance with the opinion of [11], [12] who say that the level of an instrument in question measures what it should be measure. 


\subsubsection{Authentic Assessment Instrument Reliability Test Results}

The results of the reliability test of the four factors of the authentic assessment instrument for the basic forehand and backhand groundstroke based on the actions method are shown in table 9.

Table 9. Reliability Coefficient of Authentic Assessment Instruments Basic Techniques Forehand and Backhand Groundstroke Based on Actions Method

\begin{tabular}{|l|c|c|c|}
\hline Factor & $\begin{array}{c}\text { Consistency } \\
\text { Alpha } \\
\text { Cronbach }\end{array}$ & $\begin{array}{c}\text { Anava-General } \\
\text { Multifacet } \\
\text { Model }\end{array}$ & Status \\
\hline $\begin{array}{l}\text { Confidence and } \\
\text { Mental Game }\end{array}$ & 0,862 & 0,874 & reliable \\
\hline $\begin{array}{l}\text { Prior to Stroke } \\
\text { (Perception and } \\
\text { Decision Stage) }\end{array}$ & 0.892 & 0,910 & reliable \\
\hline $\begin{array}{l}\text { Perform the } \\
\text { Stroke and } \\
\text { Stroke's } \\
\text { Evaluation and } \\
\text { (Execution and }\end{array}$ & 0,883 & 0,864 & reliable \\
$\begin{array}{l}\text { Feedback } \\
\text { Stage) }\end{array}$ & & & \\
\hline $\begin{array}{l}\text { Attitude and } \\
\text { Behavior in } \\
\text { Tennis Game }\end{array}$ & 0,861 & 0,893 & reliable \\
\hline
\end{tabular}

Thus, these four factors are very fundamental and very important to be used as authentic assessment instruments for basic forehand and backhand groundstroke techniques based on the actions method learning outcomes of the Field Tennis Court for FIK UNY students.

\subsection{Discussion}

The validity and reliability of the assessment instrument is the main thing in improving the data collection process. This is stated by [13] that "validity and reliability are essential to the effectiveness of any data gathering procedure". To improve the quality of data collection, the instruments used must meet the requirements of good validity and reliability. In the measurement and assessment of the psychomotor domain, validity and reliability requirements are absolutely necessary. Likewise, when we develop an assessment instrument including an authentic assessment, the requirements for the validity and reliability of the assessment instrument must be considered.

Based on the results of data analysis through content validity tests, several tennis experts in developing authentic assessment instruments have successfully developed four factors in the assessment rubric that can be used as authentic assessment instruments for forehand and backhand groundstroke based on actions method.
The results of the content validity test of the four factors have very good validity coefficients so that they have a degree of accuracy as an assessment instrument. This is indicated by the coefficient value of Content Validity Ratio (CVR) for all factors and indicators $>0.50$. Thus, the factors and indicators of the instrument can be used as an authentic assessment instrument for basic forehand and backhand groundstroke learning outcomes for the Field Tennis Court for FIK UNY students.

This is in accordance with the opinion of [11] who said that the level of accuracy (validity) of an assessment instrument (assessment) if the coefficient of content validity (CVR) obtained 0.50 then the assessment instrument has a good level of validity. In other words, the instrument has a degree of measurement accuracy and is able to measure the items that should be measured. The same opinion was also stated by [14] who said that if the assessment instrument has a good content validity coefficient, then the instrument represents what is planned to be measured. Furthermore, [14] argue that if the items of the instrument already cover all aspects of the construct or variable to be measured, then the instrument in terms of content can be declared valid. From this opinion, it can be concluded that the four factors of the authentic assessment instrument for the basic forehand and backhand techniques based on the actions method developed can be used as an authentic assessment instrument for the learning outcomes of the Court Tennis Court for FIK UNY students.

Authentic assessment instruments for forehand and backhand groundstroke based on actions method. After the analysis, a high reliability coefficient was obtained either through the analysis of the Genova Program (Consistency Alpha Cronbach $r=0.861-0.892$ ) and Inter-Tester Reliability (Anava-General Multifacet Model $r=0.864-0.910)$. This indicates that: (1) the authentic assessment assessment instrument developed has a degree of consistency/determination among raters in assessing the same subject, (2) the five raters have the same agreement and view that the four factors are fundamental items. And is indispensable for assessing basic forehand and backhand groundstroke techniques, (3) the authentic assessment instrument is accepted and can be used as an instrument to assess the basic forehand and backhand groundstroke techniques based on the action method learning outcomes of the court tennis court for FIK UNY students. [15] says that if the instrument used to assess the skills of a sport has an intrarater and interrater reliability coefficient 0.80 , it can be said that the instrument is good for use as an assessment instrument to measure sports skills including tennis. This is in line with the opinion of [16] which says that a test is said to meet the requirements as a good test/assessment instrument if the test means "how much the degree of the measuring instrument consistently measures the measured target". 
In playing tennis to win a game is not necessarily only determined by the mastery of the forehand and backhand groundstroke techniques. There are other factors that have a significant role beyond the mastery of mastery of the two basic techniques. According to [17] the factors that influence the success of hitting forehand and backhand groundstrokes in playing tennis, including: mental competition, ability to analyze situations and read the direction of the ball (perception), decision making (decision) before hitting, accuracy of doing execution in hitting (execution), providing feedback on the results of the blow, as well as attitudes and behaviors in playing. Furthermore, Novick said that these elements take place simultaneously and quickly when playing tennis, so a quick response of motion is also needed. The Canadian Coaches Association also shared a similar opinion which said that in playing tennis the actions taken to make the tennis player imply reaction and decision making continuously in various situations. Reactions are carried out starting from the situation analysis stage, anticipating and adjusting the direction of the ball, before making decisions, making technical decisions, and evaluating strokes [18]. Therefore, the training provided is expected to allow players to automate decision-making and adapt it to the technical decisions made. Based on the expert opinion, in the preparation of the assessment instrument these components must be part of the assessment.

The results of learning tennis playing skills carried out through the $1 / 2$ match-competition system will be able to be observed carefully how self-confidence and mental attitude in playing tennis, prior to making decisions, accuracy in making decisions when making strokes, as well as the attitudes and behavior of a tennis player in implementing the four factors in doing the basic forehand and backhand groundstroke techniques while playing tennis. Through these $1 / 2$ competitions, players will experience the real game of tennis, which will always be encountered when they play (the real game of tennis). [19] said that by modifying the situation of playing tennis carried out through matches, it will involve students cognitively, stimulate student interest, allow students to play more games, and giving students the opportunity to transfer concepts from one game to another. To be able to observe carefully the four factors, an observation sheet and an assessment sheet are needed to see the performance displayed.

\section{CONCLUSION}

The need for authentic assessment instruments for basic forehand and backhand groundstroke techniques based on actions method is very necessary to assess the learning outcomes of field tennis courses for FIK UNY students. The authentic assessment instrument model for forehand and backhand groundstroke based on actions method turned out to provide convenience for lecturers in assessing student learning outcomes authentically learning outcomes for tennis courses. The authentic assessment instrument has very good content validity and a high coefficient of reliability between raters so that it can be used as an instrument to assess the learning outcomes of the Court Tennis Court for FIK UNY students. Factors of confidence and mental play (psychology), before hitting (stage: perception and decision), execution of the stroke and its results (stage: execution and feedback), as well as attitudes and behavior in playing are fundamental factors in the authentic assessment instrument for basic forehand techniques. And backhand groundstroke based on the action method learning outcomes of the Court Tennis Court for FIK UNY students.

\section{ACKNOWLEDGMENTS}

The author would like to thank the research team for their help and cooperation. Likewise, the experts and teachers of tennis courses who have provided assessments and input on the authentic assessment instrument model developed by researchers. Thanks are also conveyed to the students of FIK UNY who have been willing to be the subjects of this research.

\section{REFERENCES}

[1] Lund J. L. dan Kirk, M. F. (2010). Performance Based Assessment for Middle and High School Physical Education. USA: Human Kinetics Publishers.

[2] Suzann Schiemer. (2000). Assessment Strategies Elementary Physical Education. USA: Human Kinetics Publishers.

[3] Mueller, John. (2009). Authentic Assessment Toolbox. Nort Central College (http://www.noctrl.ed/Napervile,htt://jonathan.mueller.faculty.n ctrl.edu/toolbox/index.htm (Diambil 27 Agustus 2009).

[4] Crespo, Miguel dan Miley, Dave. (1998). Advanced Coaches Manual. Bank Lane, Roehampton, London: International Tennis Federation

[5] Elderton. (2013). Principles of Modern Coaching Methodology an Evolution. ITF Coaching and Sport Science Review 2013; 60 (21): 8-9.

[6] Crespo, M. \& Reid, M. (2009). Coaching Beginner and Intermediate Tennis Players. ITF: London.

[7] Tennis Canada Coaching Certification System. (1988). Coach 1 ("Assistant Coach"). Canada: Coaching Assosiation of Canada.

[8] Veal, M. (1992). The Role of Assessment in Secondary In Physical Education: A Pedagogical View. Journal of Physical Education, Recreation \& Dance, 63 (7), 88-92.

[9] Sugiyono. (2019). Metode Penelitian Kuantitatif Kualitatif \& RnD. Bandung: Alfabeta.

[10] Kutlu, M. Yapici., Demirkan E. et. al. (2014). Reliability and Validity of New Test on Agility and Skill for Children Soccer Players. Central European Journal of Sport Sciences and Midicine, 6(2), 5-12.

[11] Nitko, J. A., \& Brookhart, S. M. (2011). Educational Assessment for Students. (Sixth Ed.). Boston: Pearson Education, Inc. 
[12] Azwar, S. (2012). Reliabilitas dan Validitas. Yogyakarta: Pustaka Pelajar.

[13] Best, John W. \& Kahn, James V. (2010). Research in Education; PHI Learning Private Limited: New Delhi.

[14] Borg, W. \& Gall, M. D. (2003). Education Research. New York. Interstate Book.

[15] Strand, Bradford N., Wilson, Rolayne. (1993). Assesing Sport Skills. United State of America: Human Kinetics Publishers.

[16] Sukadji, Sutarlinah. (2000). Menyusun dan Mengevaluasi Laporan Penelitian. Jakarta: Universitas Indonesia Press.

[17] Novick, Ari. (1988). Coach 1 Assistant Coach (The Actions Method). Canada: National Coaching Certification Program.

[18] https://www.tpacanada.com/sites/default/files/ TEACHING\%20METHODS\%20Canada\%20Conference.pdf).

[19] Wright, Steven, Mc Neillb, Michael, Joan Fryb, \& Wang John. 2005. Teaching Teachers to Play and Teach Games. Physical Education and Sport Pedagogy. Vol. 10, 1, 61-82. 